\title{
Mobilidade de capitais e crescimento econômico: elementos para uma síntese teórica ${ }^{1}$
}

\author{
Sérgio F. Meyrelles Filho ${ }^{2}$ \\ Frederico Gonzaga Jayme Jr. ${ }^{3}$ \\ Gilberto de Assis Libânio ${ }^{4}$
}

\section{Resumo}

Este trabalho objetiva analisar teoricamente a conexão entre abertura da conta de capitais e crescimento econômico, analisando em que medida o controle de capitais contribui para o êxito de uma política voltada para o crescimento econômico. A literatura convencional em geral descarta o controle de capitais como a melhor alternativa para garantir o crescimento equilibrado, embora admita, em casos especiais, o uso de controles quantitativos temporários para evitar crises cambiais e financeiras. $\mathrm{O}$ approach teórico keynesiano de crescimento econômico, fundamentado na literatura de inspiração kaldoriana dá pistas da desejabilidade de controles como estratégia para garantir crescimento equilibrado no balanço de pagamentos. A evidência empírica também dá suporte a essa alternativa. As conclusões, portanto, conduzem à importância de estratégias de controles de capitais para coadjuvar no crescimento sem restrições no balanço de pagamentos.

Palavras-chave: Controle de capitais; Balanço de pagamentos; Conta financeira.

\section{Abstract \\ Capital mobility and economic growth: towards a theoretical synthesis}

This paper aims at exploring theoretically the literature regarding capital flows liberalization and economic growth. Precisely, we intend to analyze the role of capital controls over economic growth. Mainstream literature discard capital controls as an alternative to foster economic growth, although admits, in few situations, temporarily quantitative capital controls to avoid financial crisis. The Keynesian approach to economic growth by means of Kaldorian literature is the key to understanding capital controls as an strategy to warrant growth under balance of payments equilibrium. Conclusions highlight the role of capital controls in helping economic growth.

Key words: Capital controls; Balance of payments; Financial account.

JEL F43, F32.

\section{Introdução}

A década de 1990 foi caracterizada por um elevado crescimento dos fluxos internacionais de capitais, não apenas entre os países desenvolvidos mas, notadamente, entre estes e os países em desenvolvimento (Prasad et al., 2004).

(1) Trabalho recebido em dezembro de 2006 e aprovado em setembro de 2008.

(2) Professor de Economia da Universidade Federal de Goiás (UFG), Goiânia, GO, Brasil. E-mail: fornazier@face.ufg.br.

(3) Professor da Universidade Federal de Minas Gerais (UFMG), Belo Horizonte, MG, Brasil. E-mail:

(4) Professor da Universidade Federal de Minas Gerais (UFMG), Belo Horizonte, MG, Brasil. E-mail: 
Nesse contexto, desde então, embora alguns desses países, como China e Índia, tenham continuado a apresentar um vigoroso processo de crescimento sustentado, vários outros foram severamente afetados por crises financeiras/cambiais, concomitantemente ao processo de integração financeira internacional. Diante da instabilidade mundial e dos elevados custos econômicos e sociais resultantes dessas crises, há um vigoroso esforço de pesquisa dos economistas para estudar as prováveis conexões entre mobilidade internacional de capitais e performance macroeconômica, com especial atenção para o caso dos países menos desenvolvidos.

A relação entre o grau de abertura aos capitais internacionais e o crescimento econômico tem sido objeto de um crescente debate teórico e empírico e o objetivo deste artigo é empreender uma análise teórica sobre o tema, com o objetivo de construir um referencial analítico para o entendimento da relação entre crescimento econômico e mobilidade internacional de capitais. Boa parte dos estudos empreendidos até então procuram analisar o papel dos fluxos de capitais no gerenciamento da política econômica, deixando a relação entre controle de capitais e crescimento em segundo plano. De início, apresentamos os principais argumentos em favor da liberalização dos movimentos internacionais de capital e, em seguida, as principais qualificações apresentadas no âmbito da abordagem convencional, relativas à necessidade de um adequado sequenciamento das reformas econômicas. Identificados os elementos fundamentais da abordagem mainstream, enfocamos a critica pós-keynesiana aos argumentos liberais e sua defesa dos controles de capitais. Abordamos, ainda, uma questão fundamental no referido debate, qual seja, a relação entre políticas macroeconômicas, regimes cambiais e mobilidade de capitais. Concluindo, são apresentadas considerações teóricas sobre a desejabilidade do controle de capitais e sobre a necessidade de estudos adicionais acerca de sua relação com o processo de crescimento econômico de longo prazo.

\section{$1 \mathrm{O}$ debate teórico}

Conforme sugerido por Edwards (1999), os economistas, há um bom tempo, discutem sobre os possíveis benefícios da livre mobilidade internacional de capitais. Vale aqui lembrar que no contexto das discussões sobre a nova ordem financeira internacional que resultaram no arcabouço institucional acordado em Bretton Woods, no ano de 1944, John Maynard Keynes, um ativo participante, chamava atenção para a natureza especulativa dos mercados financeiros e para os possíveis perigos imanentes à liberalização financeira internacional (Moggridge, 1980). Também nessa linha de argumentação, já na década de 1970, James Tobin (1978) apresentou uma proposta de proteção dos mercados reais da volatilidade dos mercados internacionais de capital. A ideia central de Tobin era interferir na 
engrenagem dos mercados financeiros internacionais mediante a adoção simultânea pelos diversos países de um pequeno imposto ad valoren sobre transações cambiais (que ficaria conhecido na literatura como "Tobin tax"), reduzindo assim os incentivos para as atividades puramente especulativas nesses mercados. ${ }^{5}$ Segundo Edwards (1999), diante do crescente reconhecimento das dificuldades, de ordem técnica e política, associadas a esquemas grandiosos e universais dessa natureza, as recentes discussões sobre o futuro do sistema monetário internacional têm se voltado progressivamente para os possíveis méritos de iniciativas de política econômica domésticas (mais modestas, segundo ele) no sentido de restringir a mobilidade dos fluxos de capital, ou seja, para os prós e contras do controle de capitais.

\subsection{Argumentos favoráveis à liberalização do fluxo de capitais}

No debate teórico recente sobre mobilidade de capitais e crescimento, quatro principais argumentos têm sido apresentados em prol da remoção dos instrumentos de controle, todos eles baseados (em maior ou menor grau) na hipótese fundamental de que mercados internacionais de capital competitivos são eficientes. A ausência de obstáculos ao seu livre funcionamento são capazes de promover uma alocação ótima de recursos, canalizando-os para seu uso mais produtivo e evitando, assim, desperdícios. A hipótese de mercados eficientes, nesse contexto, implica fundamentalmente que todas as informações relevantes para as decisões otimizadoras dos agentes econômicos (racionais) são incorporadas e fornecidas explicitamente pelo sistema de preços. Nesse sentido, mediante a observação do comportamento dos preços no mercado, todas essas informações tornam-se disponíveis e os agentes têm acesso simétrico a elas.

\subsubsection{Acumulação de capital e convergência}

O primeiro, e mais frequente, argumento favorável à livre mobilidade de capitais é de que esta atuaria no sentido de reduzir as disparidades internacionais em termos de desenvolvimento ao intensificar o processo de acumulação de capital nos países mais pobres. O argumento é usualmente apresentado tendo como referencial analítico modelos neoclássicos de crescimento exógeno, utilizando-se o conceito de convergência condicional. Esses modelos pressupõem uma tecnologia de produção caracterizada por retornos constantes de escala e rendimentos marginais positivos e decrescentes com relação à acumulação dos fatores capital e trabalho.

(5) Uma análise crítica da proposta de Tobin, em linhas pós-keynesianas, é desenvolvida por Davidson (1997).

Economia e Sociedade, Campinas, v. 18, n. 3 (37), p. 439-467, dez. 2009. 
O modelo prevê que cada economia converge para o seu próprio estado estacionário e que a velocidade dessa convergência é inversamente relacionada com a distância que a separa desse ponto. Assim, um menor valor inicial do estoque de capital, e, portanto, do produto per capita tenderia a gerar, dentro dessa perspectiva, uma taxa de crescimento per capita mais elevada, uma vez que controlemos para os determinantes do steady-state. Essa condição garante a condicionalidade aos valores dos parâmetros estruturais que determinam o equilíbrio de longo prazo, é o que confere à convergência predita pelo modelo um caráter condicional. ${ }^{6}$ A propriedade de convergência condicional permanece igualmente válida nos modelos neoclássicos de crescimento exógeno do tipo Ramsey-Cass-Koopmans, que endogenizam a determinação da taxa de poupança da economia.

Voltando à questão da mobilidade internacional de capital: conforme já ressaltamos, admite-se dentro desse paradigma que mercados internacionais de capital mais abertos e competitivos permitem uma alocação internacional de recursos mais eficiente, canalizando a poupança mundial para seu uso mais produtivo. Dessa forma, uma vez removidos os obstáculos à sua livre mobilidade o capital fluiria de onde ele é relativamente abundante, para onde ele é relativamente escasso e, portanto, para onde sua produtividade marginal é mais elevada, reduzindo assim disparidades (Eichengreen et al., 1998). Em termos dos modelos de crescimento exógeno, esse movimento resultaria numa intensificação do processo de convergência condicional acima referido. Ou seja, coeteris paribus, o influxo de capital externo permitiria às economias menos desenvolvidas intensificar seu ritmo de acumulação de capital, e acelerar seu processo de convergência para o steady-state relativamente às economias inicialmente mais ricas em capital (Barro et al., 1995, p. 114).

Contudo, é importante lembrar que nesses modelos a acumulação de capital, devido aos rendimentos marginais decrescentes, não seria capaz de sustentar o crescimento da economia no longo prazo, o qual dependeria do ritmo de progresso tecnológico ou, em outros termos, da taxa de crescimento da produtividade. Gourinchas e Jeanne (2003) argumentam que, para o típico país emergente, os ganhos de bem-estar associados à intensificação do processo de convergência condicional tenderiam a ser relativamente limitados em virtude de seu caráter transitório, e que a simples realocação internacional de capital seria, em si mesma, incapaz de conduzir a um substancial processo de convergência

(6) Em contraposição ao conceito de convergência absoluta, onde incondicionalmente as economias mais pobres tenderiam a crescer mais rapidamente que as economias mais ricas. Assim, sob convergência condicional torna-se possível que uma economia capital-abundante cresça mais aceleradamente que uma economia capitalescasso, durante a dinâmica de transição se, por exemplo, sua taxa de poupança for suficientemente mais alta e seu steady-state por conseguinte mais elevado. Veja Barro e Sala-i-Martin (2004). 
entre países mais e menos desenvolvidos. Isso porque suas diferenças são fundamentalmente explicadas não em termos de sua dotação relativa de fatores de produção, mas em termos de sua eficiência alocativa doméstica, notadamente em termos da produtividade dos fatores.

Entretanto, esses mesmos autores são enfáticos ao afirmar que a integração financeira internacional poderia gerar benefícios significativos para os países menos desenvolvidos em termos do crescimento de longo prazo se, ao mesmo tempo em que realocasse capital internacionalmente (promovendo a eficiência alocativa internacional), ela promovesse ganhos de produtividade nessas economias (contribuindo para a eficiência alocativa doméstica). Um importante canal para a concretização desses benefícios seria o investimento direto estrangeiro. Esse tipo de investimento contribuiria de duas principais formas para o crescimento da produtividade do trabalho nos países emergentes. Diretamente, mediante a introdução de tecnologias mais avançadas, e indiretamente encorajando ganhos de eficiência por parte das firmas locais em razão da maior concorrência. Os potenciais benefícios do investimento direto estrangeiro são ressaltados também por Prasad et al. (2004).

\subsubsection{Administração eficiente de riscos}

Os modelos neoclássicos de crescimento econômico são usualmente construídos tendo como pressuposto (implícito ou explícito) um ambiente não estocástico. ${ }^{7}$ Nesse sentido, ignoram as possíveis complicações introduzidas pela existência da incerteza, que no âmbito desse paradigma é reduzida a um risco probabilístico calculável. Todavia, uma vez reconhecida a importância do fator risco para uma análise de longo prazo, a integração financeira internacional poderia (argumentam seus defensores) ter um impacto positivo sobre o crescimento econômico devido a uma alocação mais eficiente dos riscos. Essa maior eficiência seria derivada fundamentalmente da expansão das oportunidades de diversificação de portfólio, gerada pelo livre movimento de capitais. Assim, segundo Fischer (1998, p. 3): "International capital flows expand the opportunities for portfolio diversification and thereby provide investors in both industrial and developing countries with the potential to achieve higher riskadjusted rates of returns."

Em termos mais exatos, a literatura tem enfatizado dois principais canais mediante os quais uma maior diversificação de carteiras poderia contribuir para o crescimento. O primeiro diz respeito à possibilidade de evitar riscos, ou

(7) Obstfeld e Rogoff (1996, p. 430), num capítulo específico sobre o crescimento econômico, explicam essa opção metodológica da seguinte forma: "The reader will note we revert to perfect-foresight models for a significant portion of this chapter's analysis. The main reason for this modeling choice is that many of the key topics we want to examine center around long-run trends rather than short-term fluctuations". 
compartilhá-los internacionalmente, gerando dessa forma uma maior estabilidade nas economias domésticas. O segundo refere-se à possibilidade de realocar recursos direcionando-os para investimentos mais arriscados porém com retorno esperado mais elevado (shifting risks) (Rodrik, 1998).

Segundo Prasad et al. (2004) a essência do processo de diversificação, permitido pela globalização financeira, é que as economias participantes do comércio internacional de ativos tornam-se capazes de, por assim dizer, descarregar parte de seu risco, em termos de renda, nos mercados internacionais. Os residentes poderiam, mediante a posse de ativos externos, defender-se de flutuações associadas a choques aleatórios nas economias locais.

Por um lado, essa maior estabilidade se traduziria numa redução do custo de levantar capital para os projetos de investimento. Por outro, encorajaria as economias domésticas a especializar sua estrutura produtiva, gerando, assim, ganhos de produtividade e um maior crescimento econômico no longo prazo. Finalmente, uma menor volatilidade do consumo poderia se traduzir também em taxas mais elevadas de poupança e investimento, conforme notado por Prasad et al. (2004).

Com base em um modelo estocástico de crescimento endógeno, Obstfeld e Rogoff (1996) chamam atenção para um outro aspecto da questão. ${ }^{8}$ Segundo esses autores, a diversificação internacional poderia encorajar os diferentes países a redirecionar sua poupança para ativos mais rentáveis. No modelo, existem dois tipos de capital: capital seguro, com um retorno certo (igual à taxa real de juros da economia, livre de risco), e capital arriscado, cujo retorno é uma variável aleatória, com retorno esperado maior que o rendimento auferido mediante a posse do capital seguro. Não existem custos de natureza friccional no sentido de que os recursos podem ser movidos de uma forma de investimento para a outra instantaneamente e sem prejuízos. A análise é desenvolvida em duas etapas. Inicialmente, analisa-se o equilíbrio numa economia fechada, onde o agente representativo maximiza uma função de utilidade esperada, sujeito a uma restrição de recursos. O agente decide quanto poupar e a alocação ótima de sua riqueza, decisões essas que são independentes, dadas as hipóteses do modelo. Em equilíbrio, a fração de sua riqueza que o agente destina aos ativos arriscados é inversamente relacionada com a variância de seus retornos.

Em seguida, a análise é estendida para o caso de uma economia financeiramente integrada aos mercados internacionais. Todos os países têm as

(8) Os autores pressupõem uma tecnologia linear do tipo AK e preferências isoelásticas e logarítmicas (com elasticidade de substituição intertemporal igual a 1). Obstfeld (1994) desenvolve o mesmo tipo de argumento num modelo com grau mais elevado de sofisticação. Nesse trabalho, o autor realiza também estimativas (calibrando o modelo) dos ganhos de bem-estar proporcionados pela diversificação internacional de portfólios. Sobre esse tipo de estimativa, veja também Athanasoulis e Wincoop (2000). 
mesmas preferências e tecnologias que antes, porém os retornos dos investimentos arriscados são imperfeitamente correlacionados internacionalmente. Nesse contexto, uma economia pode também adquirir capital arriscado de outros países, algo como uma parcela de um fundo mútuo internacional de ativos arriscados. Uma vez que o retorno esperado dos ativos arriscados é o mesmo em todos os países, o retorno esperado do fundo mútuo é o mesmo que aquele esperado dos investimentos arriscados domesticamente, isto é, nas economias fechadas. Entretanto, em decorrência da diversificação global de portfólios, a variância dos retornos arriscados é reduzida. Esse é o ponto-chave do modelo. A menor variância induz cada um dos países a alocar uma fração relativamente maior de sua riqueza em ativos arriscados e, com isso, o crescimento esperado dessas economias também aumenta. Os autores ressaltam, contudo, o fato de que esses resultados são gerados no contexto de um modelo onde os rendimentos marginais do capital são constantes. Em um modelo com rendimentos decrescentes, afirmam, a diversificação internacional de portfólios gera um efeito positivo permanente sobre o nível, mas não sobre o crescimento do produto esperado. ${ }^{9}$

\subsubsection{Desenvolvimento dos sistemas financeiros domésticos}

Um terceiro argumento favorável à abertura da conta de capitais destaca os potenciais benefícios do livre movimento internacional de capitais em termos do desenvolvimento dos sistemas financeiros domésticos. Na linha sugerida por Levine (1997), o sistema financeiro desempenha um papel central no funcionamento de uma economia de mercado, qual seja, facilitar a alocação de recursos, no espaço e no tempo, num ambiente incerto. Essa função geral, argumenta esse autor, pode ser decomposta em cinco subfunções básicas, a saber: a) Facilitar a administração de riscos; b) Alocar recursos; c) Exercer controle corporativo; d) Mobilizar poupanças; e) Facilitar o comércio de bens e serviços.

O grau de eficiência com que essas diferentes funções são exercidas reflete o grau de desenvolvimento do sistema financeiro. Este, por sua vez, afetaria positivamente o crescimento econômico mediante dois canais fundamentais, ou seja, elevando a taxa de acumulação de capital e acelerando o ritmo de progresso tecnológico na economia. Conforme ressaltado por Levine, no âmbito de modelos de crescimento endógeno, ambos esses canais poderiam levar a um maior crescimento econômico no longo prazo. ${ }^{10}$

Ainda segundo esse mesmo autor, existem consideráveis disparidades internacionais no que tange ao desenvolvimento dos sistemas financeiros

(9) E onde, portanto, a acumulação de capital pode sustentar o crescimento econômico no longo prazo.

(10) No âmbito dos modelos neoclássicos de crescimento exógeno, conforme já notamos, a acumulação de capital não é capaz de sustentar o crescimento econômico no longo prazo, o qual depende do ritmo de progresso tecnológico. Este, por sua vez, não é explicado endogenamente (é dado exogenamente). 
domésticos. Partindo dessa percepção, diversos analistas apontam para os possíveis benefícios da integração financeira no sentido de incrementar a eficiência dos setores financeiros locais. Dois principais mecanismos têm sido destacados nesse contexto. Primeiramente, argumenta-se que a liberalização geraria ganhos de eficiência ao possibilitar a especialização na oferta de serviços financeiros, permitindo explorar vantagens comparativas, em analogia com a teoria do comércio internacional. (Eichengreen et al., 1998). Em segundo lugar, ressalta-se que, em virtude da maior concorrência, representada pelas instituições não residentes, os intermediários locais seriam forçados a incrementar a qualidade dos serviços financeiros, introduzir inovações e aumentar sua produtividade, assegurando-se assim uma intermediação de recursos mais eficiente. ${ }^{11}$

\subsubsection{Políticas econômicas mais disciplinadas}

Finalmente, um outro argumento geral favorável à liberalização dos fluxos de capital ressalta seu possível efeito disciplinador sobre a condução das políticas econômicas domésticas. Assim, dada a livre mobilidade de capitais, as autoridades econômicas nacionais seriam forçadas a garantir melhores instituições e tenderiam a seguir políticas macroeconômicas mais confiáveis, uma vez que comportamentos irresponsáveis (na área monetária, como um exemplo) poderiam ser punidos com uma fuga de capitais. Ao contrário, os governos que seguissem políticas exemplares, comprometidas com a estabilidade de preços e a garantia dos direitos de propriedade, seriam capazes de atrair potenciais investidores, aumentando assim as possibilidades do país.

Bartolini e Drazen (1997) chamam atenção para o efeito sinalizador das políticas relativas à conta de capital. De acordo com esses autores, a livre mobilidade de capitais, além de possibilitar maior flexibilidade para a alocação corrente de capital, poderia sinalizar uma menor probabilidade de imposição subsequente de controles e, em termos mais gerais, políticas futuras provavelmente mais favoráveis ao investimento. Assim, a remoção dos instrumentos de restrição à saída de capitais poderia levar, num segundo momento, ao aumento dos influxos de capital estrangeiro. Por outro lado, enfatizam Bordo et al. (2001), governos encobertos pela sombra do controle de capitais com frequência sucumbiriam à tentação de realizar políticas expansionistas, aumentando a probabilidade de crise cambial nas respectivas economias. Essas crises, por seu turno, invariavelmente implicariam desperdício de recursos com prejuízos para o crescimento econômico.

(11) Nesse contexto, autores como Gourinchas e Jeanne (2002) e Prasad et al. (2004), chamam atenção para os benefícios auferidos pelos países menos desenvolvidos como decorrência do investimento direto estrangeiro de natureza financeira. Segundo seus argumentos, a presença de bancos estrangeiros geraria uma série de ganhos para esses países, dentre eles, um acesso mais fácil aos mercados internacionais. 
Uma expressão entusiasmada de fé no efeito disciplinador dos mercados internacionais de capital é apresentada por Dornbusch (1998). ${ }^{12}$ Segundo o autor, os países deveriam urgentemente reconhecer que o escopo para a realização de políticas econômicas discricionárias tem se tornado extremamente limitado, e que os mesmos têm muito a ganhar com a disciplina imposta pelos mercados de capital. Assim, segundo Dornbusch:

A modern answer to the question of integration with the world capital is enthusiastically positive. The capital market fulfills an important supervisory function over economic policy. Governments may be disinclined to have the bond market look over their shoulders, but savers and investors should welcome it. This message is clear from a decade of policy reorientation in United States and Europe. Now, governments' first thoughts are of the bond market, and as a result, their policymaking has become more disciplined. Emerging economies can even less afford to be at odds with the world capital market. Because most of them need capital, they should not switch off the monitor that helps provide it on better and more lasting terms ( p. 24).

Segundo essa perspectiva, a disciplina imposta pelos mercados favoreceria não apenas um maior influxo líquido de capitais externos mas também uma maior eficiência alocativa nas economias domésticas, aumentando assim a produtividade dos fatores e o crescimento econômico. Um modelo formal que desenvolve esse argumento é apresentado por Gourinchas e Jeanne (2002). Esse modelo ilustra que o compromisso com a mobilidade de capitais (mesmo que por um horizonte temporal relativamente curto) produz os necessários incentivos para que o governo se comprometa com políticas saudáveis do ponto de vista dos investidores por um período suficientemente longo para que os investimentos se realizem. Isso, por sua vez, gera um equilíbrio em que os investimentos são realizados no setor formal e mais produtivo da economia (sujeito à taxação) e não no setor informal e menos produtivo (não sujeito à taxação). Como resultado, a produtividade agregada da economia aumenta e, com ela, o crescimento de longo prazo.

\subsection{Informação assimétrica, distorções domésticas e o sequenciamento das reformas}

Não obstante a inapelável força desse conjunto de argumentos em favor da liberalização, um número crescente de trabalhos dentro dessa literatura têm chamado atenção para os possíveis perigos (por uma ótica alocativa) derivados da existência de assimetria de informação nos mercados financeiros, ou decorrentes de distorções no funcionamento das economias domésticas. Nesse sentido, tais contribuições geralmente enfatizam a importância de um adequado sequenciamento das reformas econômicas para que os potenciais benefícios da livre mobilidade de capitais de fato se concretizem.

(12) Confira também Obstfeld (1998).

Economia e Sociedade, Campinas, v. 18, n. 3 (37), p. 439-467, dez. 2009. 
No âmbito da teoria neoclássica do equilíbrio geral sob incerteza, uma situação de simetria de informação é definida como um contexto em que todo e qualquer agente é igualmente capaz de identificar o estado da natureza vigente num dado momento. Por outro lado, quando uma das partes de uma transação econômica possui menos informação que as demais diz-se que a informação é assimétrica no respectivo mercado. Greenwald e Stiglitz (1986) ressaltam que, uma vez reconhecida a existência de informação imperfeita, os resultados derivados do livre funcionamento de mercados competitivos podem não ser eficientes. Assim, de acordo com Stiglitz (2000): “... whenever information is imperfect, markets are essentially never constrained Pareto efficient in marked contrast to standard results for competitive markets with perfect information" (p. 1079).

No que se refere aos mercados internacionais, afirma-se, os problemas de informação tendem a ser mais acentuados, uma vez que os agentes estariam separados por uma maior distância física e cultural. ${ }^{13}$ Ademais, a situação poderia ser ainda pior caso as operações envolvessem países menos desenvolvidos, nos quais a capacidade de obter e processar informações é relativamente limitada (veja Eichengreen, 2001). A literatura destaca três tipos fundamentais de problemas comumente originados a partir de informação assimétrica nos mercados financeiros, quais sejam, a seleção adversa, o risco moral e o comportamento de manada.

Uma referência obrigatória nessa discussão, sem dúvida, é o modelo de racionamento de crédito desenvolvido por Stiglitz e Weiss (1981), que destaca o processo de seleção adversa. O modelo considera dois tipos de agentes, bancos e potenciais tomadores de empréstimo. Os bancos determinam o preço dos empréstimos, isto é, a taxa de juros, de modo a maximizar o retorno esperado de suas operações. Os diferentes tomadores de empréstimos diferem em qualidade, ou seja, em termos de sua probabilidade de pagar os empréstimos. Todavia, é difícil para os bancos identificarem os bons tomadores, vale dizer, os menos arriscados, dos ruins, que representam uma maior chance de não pagamento. Em termos mais precisos, os tomadores de crédito possuem mais informação sobre sua capacidade de pagar os empréstimos do que os bancos, que não podem avaliar de forma precisa a qualidade individual de cada potencial cliente. Por sua vez, os tomadores de pior qualidade estão em regra dispostos a aceitar uma taxa de juros mais elevada, tendo em vista que eles percebem que sua probabilidade de pagar os

(13) Calvo e Mendoza (2005) ressaltam que as fricções em termos de informação desempenham um papel consideravelmente mais acentuado nos mercados internacionais. Nesse sentido, prossegue o argumento, o investimento internacional envolveria uma série de riscos não apresentados pelos investimentos domésticos, como por exemplo, riscos associados à imposição de instrumentos de controle de capitais e mesmo risco de expropriação. 
empréstimos é relativamente pequena. Com o objetivo de maximizar seu retorno esperado, e diante de sua limitação informacional, os bancos cobram uma taxa de juros condizente com a qualidade média dos potenciais tomadores de crédito. $\mathrm{O}$ problema é que essa taxa média é superior àquela considerada justa pelos bons tomadores, os quais são assim desincentivados a buscar financiamento no mercado, e inferior à considerada justa pelos tomadores de pior qualidade, os quais têm então um incentivo para obter crédito.

Configura-se dessa forma o que se denomina de seleção adversa no mercado de crédito. Se, dada a taxa de equilíbrio assim fixada pelos bancos, a demanda por fundos excede a oferta, ocorre, portanto, um racionamento de crédito na economia. A essência do argumento é a mesma no caso dos mercados domésticos e dos mercados internacionais. Como decorrência do mecanismo de seleção adversa, a assimetria de informação tenderia assim a gerar uma alocação subótima de recursos.

Um segundo tipo de problema, tipicamente associado à informação assimétrica, é o chamado risco moral. Assim, sob informação assimétrica nos mercados financeiros, tomadores de empréstimo poderiam engajar-se em projetos excessivamente arriscados do ponto de vista dos emprestadores, os quais não teriam como avaliar plenamente o caráter da aplicação dos recursos. Diante da percepção do risco moral, os emprestadores poderiam se tornar relutantes em conceder crédito, gerando assim um racionamento e uma consequente contração dos investimentos na economia.

Mas, além do racionamento, o risco moral poderia também resultar na geração de crises financeiras/cambiais, em países onde extensivas redes de segurança financeira, criadas pelos Bancos Centrais locais, pretensamente resguardam os empréstimos concedidos pelo sistema bancário doméstico. Nesse contexto, Krugman (1998) ressalta que em economias inadequadamente reguladas, o risco moral associado ao compromisso das autoridades monetárias de resguardar o sistema bancário pode levar este último a uma expansão excessivamente arriscada dos seus empréstimos diante de ingressos maciços de recursos externos, reduzindo o conteúdo informativo dos preços dos ativos e gerando uma situação de instabilidade financeira crescente. Mishkin (1999) destaca que os emprestadores internacionais, por sua vez, confiantes no eventual resgate dos seus empréstimos em caso de crise, teriam poucos incentivos para monitorar adequadamente os bancos domésticos.

Mishkin observa que, embora os movimentos internacionais de capital tenham efetivamente contribuído para a referida crise, seu comportamento deve ser entendido essencialmente como um sintoma e não como uma causa fundamental da instabilidade financeira, originada, na verdade, pelo 
comportamento imprudente dos bancos locais num contexto de inadequada supervisão e regulação financeira, característica notória de economias emergentes.

Por fim, argumenta-se que, sob informação assimétrica nos mercados de capital, os investidores tenderiam a apresentar comportamento de manada, definido como uma situação na qual o comportamento de um agente, ou de determinado grupo, é seguido (imitado) por todos os demais agentes ou por uma parcela expressiva destes. Esse padrão de comportamento pode refletir uma decisão otimizadora por parte dos seguidores, quando estes acreditam estar menos bem informados que o investidor de referência. O provável resultado seria uma maior volatilidade dos preços dos ativos, e, no limite, mesmo a precipitação de crises financeiras. ${ }^{14}$

Um outro fenômeno, possivelmente relacionado ao comportamento de manada, é o assim chamado efeito contágio, que corresponde, em linhas gerais, a um contexto onde um choque externo é, em alguma medida, transmitido para outras economias. ${ }^{15}$ Calvo e Mendoza (2005) apresentam um modelo no qual o contágio pode surgir como decorrência de uma decisão racional dos investidores internacionais de não pagar por informações específicas relativas a um determinado país, o que torna suas decisões suscetíveis à influência de rumores sobre a situação concreta dessa economia, os quais podem não ser fundamentados.

Num contexto assim descrito, uma situação de instabilidade financeira em determinado país (emergente, digamos) poderia plausivelmente resultar numa saída maciça de capitais em outras economias, a priori, consideradas pelos investidores internacionais como estruturalmente similares, mesmo que os fundamentos nessas economias não justificassem efetivamente uma situação de crise. $^{16}$

Problemas de informação à parte, diversos autores do mainstream enfatizam que, mesmo em um ambiente onde a informação é perfeita, a livre mobilidade internacional de capitais poderia resultar numa alocação ineficiente de recursos e em prejuízos para o crescimento econômico, em decorrência de distorções de natureza econômica ou de ordem institucional, ainda hoje existentes em boa parte do mundo em desenvolvimento. Especificamente com relação às barreiras ao comércio internacional de bens e serviços, Cooper (1998) afirma que, num contexto de protecionismo comercial, os influxos de capital externo poderiam

(14) Para uma boa revisão crítica sobre o comportamento de manada, ver Blecker (1999).

(15) Para uma boa revisão da literatura sobre esses modelos, ver Curado (2001).

(16) É interessante notar nesse contexto que, não obstante esse tipo de análise, Calvo e Mendoza (2005) exibem uma posição visivelmente cética com relação à possível utilização de instrumentos de controle de capitais. Nesse sentido, afirmam: "In the final analysis, the dismal economic performance of the developing world during the 1980 serves as a dramatic reminder of the fact that simply shutting down or limiting access to capital markets can have catastrophic consequences" (p. 279). 
ser direcionados para setores em que o país receptor tem desvantagens comparativas, resultando assim em efeitos negativos tanto do ponto de vista da alocação internacional de recursos, quanto para a economia doméstica.

Uma série de outras possíveis distorções são comumente citadas na literatura, dentre elas: a) Políticas macroeconômicas pouco sólidas; b) Sistemas legais imperfeitos; c) Corrupção na esfera governamental e d) Padrões de auditoria e contabilidade pouco confiáveis na esfera privada. ${ }^{17}$

Reconhecidas essas potenciais distorções e os possíveis perigos associados à informação assimétrica, a literatura convencional tem crescentemente enfatizado a importância de um adequado sequenciamento das reformas voltadas para o mercado. Conforme sublinhado por Williamson e Mahar (1998), a moderna discussão sobre o sequenciamento da liberalização financeira tem suas origens na década de 1980, inicialmente como resposta às experiências malsucedidas de países como Chile e Argentina no sentido de remover seus mecanismos de repressão financeira, no final dos anos $1970 .{ }^{18}$ Diante do retumbante fracasso, materializado em severas crises macroeconômicas em princípios da década seguinte, emergiu uma literatura que procurava explicar o infortúnio desses países em termos de um sequenciamento inadequado do processo de liberalização. Dentre outros aspectos, notava-se que a abertura prematura aos movimentos internacionais de capital havia contribuído de forma decisiva para o exponencial crescimento do endividamento externo dessas economias. No período mais recente, a sucessão de crises cambiais em mercados emergentes, iniciada com a crise mexicana em 1994, e a instabilidade financeira internacional generalizada contribuíram incisivamente para que essa discussão adquirisse um vigor redobrado. Nos dias de hoje, existe também um reconhecimento mais claro, no âmbito da comunidade financeira internacional, de que a utilização temporária de controles de capitais é algo que merece ser estudado. O próprio Kenneth Rogoff, então diretor de pesquisas do Fundo Monetário Internacional, parece concordar:

Hard work remains to be done on capital account liberalization and its sequencing with other policies to find the point at which the benefits to further capital market integration stop exceeding the costs[...] In the meantime, there seems to be a good case for keeping an open mind on the issue of capital controls and debt-especially when debating ways to better immunize the global financial system against crises in the twenty-first century (2002, p. 4).

Vários autores enfatizam diferentes aspectos delineadores do que seria em sua visão um adequado sequenciamento. Todavia, tende a existir um consenso no que se refere a determinados aspectos, por exemplo, quanto à importância de se

(17) Confira, por exemplo Dooley (1996); Fischer (1998); Eichengreen et al. (1998), Bordo et al. (2001), Prasad et al. (2004), dentre outros.

(18) Veja Aizenman (2005). 
garantir um ambiente de estabilidade macroeconômica, com baixa inflação e deficits externos sustentáveis, previamente à liberalização dos movimentos de capitais. $\mathrm{Ou}$, ainda, sobre a desejabilidade de reformas institucionais que atuem no sentido de restringir a corrupção, garantir direitos de propriedade e aumentar a transparência em todas as esferas da economia. Um outro requisito, enfaticamente destacado por inúmeros economistas, sobretudo por aqueles que discutem os problemas advindos da informação assimétrica, diz respeito à necessidade de se garantirem sólidos arcabouços de regulação e supervisão prudencial dos sistemas financeiros domésticos (particularmente no que se refere ao sistema bancário).

Essa discussão sobre o sequenciamento abre espaço para uma possível interpretação com relação à existência de efeitos diferenciados da mobilidade internacional de capitais em países com graus distintos de desenvolvimento. $\mathrm{Ou}$ seja, emerge nesse sentido uma possível rationale teórica para justificar a ideia de que os movimentos de capitais podem ter um efeito negativo sobre o crescimento econômico em países pouco desenvolvidos, ao contrário do que ocorre nas economias mais avançadas. De acordo com Eichengreen (2001), existem fortes razões teóricas para supor que os efeitos da liberalização da conta de capitais varie em função do nível de desenvolvimento financeiro e institucional das economias domésticas. Nesse sentido, um impacto positivo sobre o crescimento ocorreria tão somente se adequadas salvaguardas fossem previamente construídas.

A posição predominante no pensamento convencional é que, uma vez garantidas as necessárias salvaguardas, a liberalização dos movimentos de capitais seria algo claramente benéfico e mesmo inevitável para as economias em desenvolvimento. ${ }^{19}$ Todavia, é possível identificar posições (parcas, é verdade) menos otimistas com relação aos prospectos da liberalização. Autores como Rodrik e Velasco (1999), por exemplo, chamam atenção para as dificuldades que mesmo os países mais avançados têm enfrentado para estabelecer mecanismos adequados de regulação e supervisão dos seus sistemas financeiros domésticos, dificuldades essas certamente muito mais sérias no caso dos países menos desenvolvidos. ${ }^{20}$ Esses autores estabelecem uma clara distinção entre fluxos de capital externo de diferentes maturidades, destacando os potenciais perigos do endividamento externo de curto prazo. Mais especificamente, desenvolvem um modelo no qual a acumulação de um grande passivo externo de curto prazo pode criar as condições necessárias para a ocorrência de uma crise cambial gerada por profecias autorrealizáveis. Rodrik e Velasco (1999) argumentam em favor da

(19) Afinal , conforme enfatizado por Fischer (1998, p. 2) todas as economias mais desenvolvidas têm, hoje, contas de capital abertas. Nesse sentido, o autor define a remoção dos controles de capitais como um passo inevitável na trajetória do desenvolvimento.

(20) Esse ponto é enfatizado também por Stiglitz (2000). 
utilização permanente de certos instrumentos de controle sobre o endividamento externo de curto prazo.

Do mesmo modo, Stiglitz $(2000 ; 2003)$ sustenta a tese de que a liberalização irrestrita dos movimentos de capital de curto prazo tem um claro impacto negativo sobre a estabilidade financeira dos países menos desenvolvidos. ${ }^{21} \mathrm{O}$ autor apresenta duas principais explicações para essa maior instabilidade. Em primeiro lugar, argumenta que fluxos de curto prazo são marcadamente pró-cíclicos, atuando assim no sentido de exacerbar flutuações econômicas, quando não constituem o elemento causador das mesmas. Em segundo lugar, a referida abertura exporia as economias domésticas às vicissitudes externas, relacionadas, por exemplo, com a percepção de risco, nem sempre fundamentada, dos investidores internacionais. A maior instabilidade tenderia a se refletir numa maior frequência (e severidade) de crises financeiras, e em termos mais gerais em efeitos adversos sobre o crescimento econômico de longo prazo. $\mathrm{O}$ autor identifica uma série de canais mediante os quais os efeitos negativos sobre o crescimento poderiam se materializar. Assim, por exemplo, o elevado risco imposto pela livre mobilidade de capitais forçaria os governos dos países emergentes a acumularem significativos montantes de reservas cambiais, em moeda forte, com elevado custo de oportunidade, implicando transferência de renda líquida para os países emissores dessas moedas, em detrimento do crescimento doméstico. Por outro lado, o risco de instabilidade faria com que as firmas domésticas (avessas ao risco) se tornassem mais relutantes em recorrer a empréstimos para realizar investimentos produtivos, os quais passariam a depender crescentemente do autofinanciamento. O resultado seria então uma retração da acumulação de capital, com fortes implicações para o crescimento econômico de longo prazo. Nesse contexto, Stiglitz endossa a ideia de que mecanismos de controle sobre os fluxos internacionais de capital de curto prazo podem ser interessantes para o crescimento econômico. Ademais, enfatiza (utilizando como exemplo a experiência recente da China) que é claramente possível impor restrições sobre os fluxos de curto prazo e ao mesmo tempo prover um ambiente favorável ao investimento direto estrangeiro, este sim, certamente muito mais relevante para o desenvolvimento dos países emergentes.

\subsection{Controle de capitais e crescimento econômico}

Uma análise da literatura convencional sobre a relação entre mobilidade internacional de capitais e crescimento econômico permite, não obstante a existência de algumas vozes dissonantes, identificar a predominância de dois princípios fundamentais. O primeiro estabelece que o crescimento econômico é

(21) As crises cambiais e bancárias seriam formas extremas desse tipo de instabilidade. Confira Stiglitz (2003, p. 514).

Economia e Sociedade, Campinas, v. 18, n. 3 (37), p. 439-467, dez. 2009. 
um fenômeno essencialmente explicado pelo lado da oferta agregada. O segundo determina que a livre mobilidade de capitais é um objetivo a ser alcançado, ao menos no longo prazo e, neste sentido, que a utilização de instrumentos de intervenção sobre esses fluxos pode ser aceitável tão somente como um recurso transitório. $^{22}$ Esses princípios têm sido incisivamente questionados por pesquisadores adeptos do princípio da demanda efetiva.

A literatura convencional geralmente assume, em perfeita consonância com a concepção neoclássica mais geral sobre o crescimento econômico, que variações autônomas da demanda agregada seriam incapazes de afetar de forma permanente o produto real da economia. O ponto de partida da análise é uma função de produção cujas propriedades específicas conferem ao processo de crescimento um caráter exógeno ou endógeno nos respectivos modelos. A tecnologia determinaria, dadas as decisões otimizadoras dos agentes e o equilíbrio nos mercados de fatores, a trajetória do produto potencial da economia ao qual a demanda agregada se ajustaria passivamente. Eventuais fricções (derivadas, por exemplo, de uma possível rigidez de preços) seriam automaticamente removidas sem afetar a trajetória de crescimento de longo prazo. ${ }^{23}$ Nesse tipo de arcabouço, políticas macroeconômicas de expansão ou contração da demanda agregada não seriam capazes de influenciar de forma direta o crescimento do produto no longo prazo. Entretanto, conforme notado anteriormente, políticas disciplinadas, isto é, comprometidas com a estabilidade e com o respeito aos direitos de propriedade, teriam um efeito salutar sobre a economia, podendo resultar num ritmo mais acelerado de acumulação de capital e em ganhos de produtividade. Por outro lado, políticas monetárias e fiscais expansionistas resultariam, via de regra, em inflação mais elevada, em geral com efeitos adversos para o crescimento. ${ }^{24}$

O segundo princípio definidor da abordagem neoclássica implica fundamentalmente que controles de capitais são custosos para o crescimento econômico se adotados como instrumentos permanentes de política econômica. Em outras palavras, embora sua existência pudesse ser tolerada ao longo de um processo de sequenciamento das reformas liberalizantes, sua incorporação definitiva à estrutura de incentivos da economia seria claramente indesejável,

(22) Dentre as referidas vozes dissonantes, talvez a mais claramente notada seja a de Joseph Stiglitz. Na seção anterior discutimos rapidamente sua posição com relação à imposição de controles de capitais. Em conexão com essas ideias, Stiglitz sugere também que políticas monetárias e fiscais excessivamente restritivas, tais como frequentemente impostas pelos programas de ajustamento do FMI, podem ter um efeito negativo sobre o crescimento econômico de longo prazo. Essa visão é consistente com um modelo de crescimento endógeno desenvolvido por esse autor no qual as recessões têm um efeito negativo sobre a trajetória de crescimento da produtividade da economia.Veja Stiglitz (1993).

(23) Confira Setterfield (2002).

(24) Ver Bernanke et al. (1999) e Sarel (1999). 
atuando no sentido de reduzir a eficiência do sistema econômico, com impactos deletérios para o crescimento das economias nacionais. ${ }^{25}$

\subsubsection{Incerteza, especulação e autonomia de políticas econômicas no paradigma pós- keynesiano}

A liberalização irrestrita dos movimentos internacionais de capital é criticada de modo contundente por economistas que se baseiam na concepção de incerteza utilizada por Keynes em sua Teoria Geral. Esses autores destacam que, num mundo caracterizado por processos não ergódicos e pela irreversibilidade do tempo, a incerteza não poderia ser reduzida a um risco probabilístico calculável e que, nesse sentido, o curso futuro dos eventos seria a priori inteiramente desconhecido. Nessa perspectiva, as ações econômicas relevantes são orientadas por expectativas, sujeitas a um forte elemento de subjetividade. Expectativas essas que podem não se concretizar e, como consequência, definir novas posições de equilíbrio.

Conforme notado por Kregel (1976), é possível identificar na obra de Keynes três modelos de determinação da renda, baseados em hipóteses alternativas no que se refere às expectativas de curto e de longo prazos, e sua interação. O primeiro, um modelo de equilíbrio estático, no qual as expectativas de longo prazo (relevantes para as decisões de investimento) são constantes, as expectativas de curto prazo (relevantes para as decisões de produção) são sempre confirmadas, e os dois tipos são independentes. O segundo, um modelo de equilíbrio estacionário, em que as expectativas de longo prazo são constantes e as expectativas de curto prazo podem ser desapontadas e, portanto, podem mudar. Porém, também nesse modelo, elas são independentes das expectativas de longo prazo. Por fim, o terceiro modelo, um modelo de equilíbrio móvel, no qual as expectativas de longo prazo podem se alterar, as de curto prazo podem ser desapontadas e existe uma interação entre ambas. Neste último modelo que, segundo Kregel, era o que melhor expressava a concepção de Keynes sobre o processo de tomada de decisão num ambiente de incerteza fundamental, existe uma clara interdependência entre o curto e o longo prazo. A partir desse modelo de equilíbrio móvel, torna-se possível identificar dois traços fundamentais da análise econômica pós-keynesiana, intimamente correlacionados. Primeiramente, o sistema econômico exibe dependência de trajetória (path dependence) de modo que o longo prazo é definido como uma sequência histórica dos resultados de curto prazo (Dutt, 1997). Seria impossível assim definir a priori qualquer equilíbrio de longo prazo, concebido como um centro de gravitação para onde a economia necessariamente converge. Em segundo lugar, em consonância com o princípio da demanda efetiva, o crescimento econômico de longo prazo é um

(25) Ver Edwards (1999) e Bernanke (2005). 
processo governado pela demanda, à qual a oferta agregada (ou o produto potencial da economia), dentro de certos limites, se ajusta. Nesse contexto, ao contrário do que ocorre na análise neoclássica, conforme aqui anteriormente referido, políticas macroeconômicas de expansão e contração da demanda agregada têm um efeito direto e permanente sobre a trajetória de crescimento da economia. ${ }^{26}$

Assim, a atividade especulativa presente nos mercados financeiros internacionais emerge como uma consequência e a incoerência e a crise são possibilidades sempre presentes. Políticas públicas direcionadas para a melhor provisão de dados e monitoramento dos sistemas financeiros domésticos nos países menos desenvolvidos, tipicamente prescritas pelos teóricos da informação assimétrica, embora certamente desejáveis, seriam também certamente incapazes de eliminar a fragilidade imanente aos mercados financeiros num contexto onde o futuro é desconhecido. Nesse sentido, afirma Grabel (2003, p. 324): “... better information is insufficient to prevent crisis. Given fundamental uncertainty and endogenous expectations, the same information might very well yield increasing investor confidence one day and a full-blown panic the next".

Controles de capitais seriam, nesse sentido, desejáveis como forma de proteger uma economia da volatilidade dos fluxos internacionais de capital num cenário de incerteza e especulação intensas, onde choques externos podem desencadear movimentos erráticos em termos dos preços dos ativos com profundas consequências adversas para os sistemas financeiros nacionais e para o crescimento econômico, conforme ilustrado pelos recentes episódios de crise financeira em mercados emergentes. ${ }^{27}$ A natureza especulativa e instável dos mercados financeiros internacionais é ressaltada também por Taylor (1998). ${ }^{28} \mathrm{De}$ acordo com esse autor, controles sobre a entrada de capitais de curto prazo poderiam desempenhar um papel-chave na prevenção de crises financeiras ao prevenir a emergência de descasamentos (mismatchs) entre as posições ativas e passivas das instituições financeiras locais, tanto no que se refere à maturidade quanto ao aspecto cambial (ou locacional) das operações.

Todavia, os pós-keynesianos advogam em favor do controle permanente de capitais, por uma segunda razão fundamental, correlata à questão da estabilidade financeira, qual seja, a de garantir a autonomia das políticas

(26) Confira, dentre outros, Arestis e Sawyer (2002), Dutt e Ross (2003), Lavoie (2004), Palley (2004) e Libânio (2005).

(27) Confira Kregel (1998; 1999), Arestis e Glickman (2002).

(28) Taylor é usualmente classificado como um autor estruturalista e não como um pós-keynesiano. Todavia, é interessante notar que sua análise sobre o funcionamento dos mercados financeiros apresenta uma clara influência minskyana. O mesmo ocorre com outros importantes autores estruturalistas. Veja, por exemplo, Foley (2003). 
econômicas domésticas e, particularmente, da política monetária. ${ }^{29}$ De acordo essa análise, num ambiente de incerteza radical, onde nada garante a priori uma situação de pleno emprego, a liberdade de um governo em empreender políticas de administração da demanda agregada (quando assim julgar necessário) seria de extrema importância, não apenas para lidar com eventuais sobressaltos ou choques, mas para garantir um elevado crescimento econômico no longo prazo. Essa autonomia, no entanto, fica comprometida num contexto de fluxos de capitais totalmente livres. Por exemplo, políticas monetárias de redução das taxas de juros domésticas com frequência esbarrariam no temor da fuga de capitais e da insolvência externa. Juros elevados, entretanto, poderiam contribuir de forma decisiva para a deterioração da situação fiscal, gerando uma situação de instabilidade crescente na economia. Por outro lado, mesmo políticas de juros altos, comprometidas com metas de inflação, digamos, poderiam também ser inviabilizadas à medida que promovessem um ingresso excessivo de recursos externos, gerando um efeito adverso sobre as contas externas por intermédio de uma valorização cambial.

Eatwell ressalta que a própria situação de instabilidade associada aos fluxos especulativos de capital poderia conferir às políticas macroeconômicas domésticas um viés recessivo, em benefício de uma pretensa credibilidade junto aos investidores internacionais e em detrimento das taxas de investimento e crescimento da economia. Em conexão com esse argumento, afirma: "High interest rates are themselves the outcome of the attempt to maintain financial stability in a potentially volatile world" (1996, p. 49). De forma similar, Grabel (2003) discute o chamado risco de soberania imposto pelo modelo liberal de integração financeira, como referência às restrições que um governo nacional, numa economia emergente, poderia enfrentar no que tange à implementação de políticas independentes em meio a uma crise financeira internacional. ${ }^{30}$ Por um lado, sob livre mobilidade dos fluxos de capital, os policy-makers poderiam ser obrigados a perseguir políticas econômicas contracionistas como um possível recurso para conter uma fuga dos investimentos internacionais. ${ }^{31}$ Por outro lado, e mais diretamente, em caso de assistência financeira externa, provida normalmente

(29) Keynes, em certa ocasião, afirmou: "A meu ver toda a administração da economia doméstica depende da liberdade de se ter a taxa de juros apropriada sem referência às taxas prevalecentes em outros lugares do mundo" (Moggridge, 1980, p. 149).

(30) Além do risco de soberania, a autora identifica outros quatro tipos de risco introduzidos pelo modelo liberal, cuja interação resultaria numa elevada vulnerabilidade dos países emergentes à ocorrência de crises financeiras. São eles o risco cambial, ou de colapso da moeda nacional; o risco de fuga de capitais; o risco de fragilidade, ou de vulnerabilidade dos tomadores de empréstimo domésticos a choques externos ou internos; e o risco de contágio, ou seja, o perigo de que a economia local seja vitimada pela instabilidade macroeconômica e financeira originada em outros países.

(31) Política essa que, conforme notado por Kregel (1998), possivelmente resultaria no agravamento da fragilidade financeira de firmas e bancos locais.

Economia e Sociedade, Campinas, v. 18, n. 3 (37), p. 439-467, dez. 2009. 
por via dos organismos multilaterais, a soberania das políticas domésticas ficaria certamente comprometida como resultado da condicionalidade associada aos empréstimos. Nas palavras da autora: “... emerging economies face constraints on their sovereignty when they receive external assistance. Assistance comes at the price of having critical policy decisions vetted by the external actors that provide support" (Grabel, 2003, p. 321). Nesse contexto, restrições à mobilidade de capitais seriam desejáveis como forma de evitar crises recorrentes e de possibilitar a implementação de políticas comprometidas com a equidade social, a estabilidade e o crescimento sustentado nos países em desenvolvimento.

\subsubsection{Política macroeconômica e regimes cambiais}

A questão da autonomia das políticas econômicas domésticas é um tema certamente controverso, de extrema divergência entre os economistas da corrente principal e os pós-keynesianos. De uma forma geral, ambos os lados tendem a reconhecer que a mobilidade internacional de capitais, em alguma medida, reduz o grau de independência conferido aos policy-makers locais.

Oreiro (2004), por exemplo, observa que, independentemente do regime cambial adotado pela economia, a mobilidade de capitais reduz dramaticamente a capacidade dos formuladores de política econômica em direcionar essa política com vistas ao atendimento de objetivos domésticos como a manutenção de um elevado nível de emprego e o crescimento sustentado. Mecanismos de controle sobre os movimentos de capital, notadamente no que se refere aos fluxos de curto prazo, seriam então indispensáveis para garantir a autonomia das políticas domésticas.

Em que sentido uma maior independência seria desejável emerge um profundo antagonismo no âmbito da teoria econômica. ${ }^{32} \mathrm{Um}$ outro ponto fundamental, que divide até mesmo os economistas convencionais, é em que medida regimes de flutuação cambial poderiam ser capazes de garantir a autonomia das políticas domésticas.

Como vimos anteriormente, um dos principais argumentos avançados em prol da liberalização dos controles de capitais ressalta exatamente o possível efeito disciplinador exercido pela livre mobilidade no que se refere à gestão macroeconômica. No que tange à política monetária, o referido argumento é construído com base em uma concepção muito clara sobre o papel desempenhado

(32) Nesse debate, afirma Eatwell (1996), faz-se necessária uma clara distinção entre a desejável exposição, por intermédio dos mercados, de possíveis contradições internas às políticas econômicas e o alinhamento, a priori, das referidas políticas com uma particular concepção teórica de eficiência econômica, no caso, o paradigma neoclássico do bem-estar. $\mathrm{O}$ autor ilustra seu argumento sublinhando que não há nada de eficiente em garantir uma taxa de inflação igual a zero e ao mesmo tempo gerar elevados níveis de desemprego, em torno de $10 \%$. 
pela moeda no sistema econômico. Nessa visão, a moeda longo prazo não produz efeitos reais na economia. Mesmo versões mais sofisticadas de política monetária observam que há uma taxa de desemprego compatível com a não aceleração da inflação e há viés inflacionário na política monetária. ${ }^{33}$

Nesse arcabouço teórico, políticas monetárias expansionistas geram, via de regra, efeitos deletérios sobre a economia. A análise convencional baseada no modelo McKinnon-Shaw sustenta o argumento de que a redução artificial da taxa real de juros, por intermédio de mecanismos de repressão financeira (como controles de capitais), resulta em prejuízos para o crescimento econômico, ao reduzir tanto a quantidade de poupança quanto a produtividade média dos investimentos realizados, nesse caso como decorrência de um processo de seleção adversa. ${ }^{34}$

No entanto, segundo essa mesma concepção geral, a política monetária deve ao mesmo tempo gozar da necessária independência no sentido de alcançar aquele que é o seu objetivo final, assegurar a estabilidade de preços. ${ }^{35}$ Os ensinamentos derivados do conhecido modelo Mundell-Fleming sugerem que é impossível uma economia conciliar, simultaneamente, a livre mobilidade de capitais, um regime de câmbio fixo e a autonomia de sua política monetária. Considerando-se a trindade impossível, e diante da integração cada vez mais acentuada dos mercados internacionais de capital, seria natural pensar que uma alternativa imediata para garantir a necessária independência da política monetária doméstica seria a adoção de um regime de flutuação cambial. Baseado nessa linha de raciocínio, Bernanke (2005) defende a implementação de um arcabouço de políticas macro composto por três elementos centrais: 1) mobilidade irrestrita dos fluxos de capital; 2) câmbio flutuante; e 3) um regime de metas de inflação. Este último elemento seria fundamental, segundo ele, para assegurar uma âncora nominal para o sistema, supondo que os países em questão sejam de fato dotados da necessária infraestrutura institucional para implementar o referido regime.

Ao menos à primeira vista, a transição para regimes de flutuação cambial parece ser uma tendência em curso no âmbito da economia mundial. De acordo com as estatísticas do Fundo Monetário Internacional, em 1970, 97\% dos países membros adotavam um regime de câmbio fixo; por volta de 1980, essa

(33) Em última análise, o sistema converge para um equilíbrio em que o nível do produto é determinado por fatores estritamente reais, pelo lado da oferta agregada. Tentativas sistemáticas de expandir a atividade econômica por intermédio de políticas de estímulo à demanda agregada seriam frustradas, resultando em aceleração da taxa de inflação (Woodford, 2003).

(34) No que se refere ao aspecto quantitativo, é nítida a concepção neoclássica de crescimento liderado pela oferta, onde a poupança determina o investimento agregado e, por conseguinte, a acumulação de capital efetivamente realizada. Para uma exposição detalhada do modelo McKinnon-Shaw, confira Fry (1995).

(35) A estabilidade dos preços domésticos possibilitaria, dentre outros benefícios, uma melhor operação dos mercados e uma maior transparência para o planejamento de longo prazo dos agentes econômicos. 
porcentagem havia se reduzido para 39\% e em 1999 era de apenas $11 \%$. Todavia, esses números têm sido questionados no âmbito do próprio mainstream por economistas como Guillermo Calvo e Carmen Reinhart (2000). Esses autores sugerem que existe atualmente na economia mundial um caso epidêmico de medo de flutuar, e que uma grande proporção dos países, sobretudo emergentes, que oficialmente declaram adotar regimes de câmbio flutuante, na verdade atuam deliberadamente no sentido de controlar as variações da taxa de câmbio, limitando sua amplitude a estreitos intervalos. Esses países utilizariam a intervenção direta no mercado de câmbio e, cada vez mais, a política monetária (de juros) para controlar o nível e a volatilidade do câmbio, tendo em vista, dentre outros motivos, problemas de credibilidade, elevado endividamento em moeda estrangeira e medo de pressões inflacionárias.

Uma importante constatação derivada da literatura do fear of floating é que a adoção de um regime de câmbio flutuante não necessariamente garante a autonomia da política monetária num ambiente de mobilidade irrestrita dos capitais internacionais. Cooper $(1998 ; 1999)$ vai ainda mais além ao afirmar categoricamente que, exceto no caso de países grandes e diversificados, com mercados financeiros bem desenvolvidos e sofisticados (como é o caso da economia norte-americana), o livre movimento de capitais e regimes de câmbio flutuantes seriam basicamente incompatíveis, tendo em vista os possíveis efeitos do câmbio sobre os preços domésticos.

Favero e Giavazzi (2005) desenvolvem um modelo no qual, dadas uma elevada mobilidade de capitais e a percepção dos investidores internacionais com relação à existência de um risco de default, um regime de metas de inflação poderia ser inviabilizado numa economia emergente com câmbio flutuante, como decorrência de choques externos. O sucesso da política monetária, afirmam, dependeria crucialmente do grau de flexibilidade conferido à política fiscal. Mais especificamente, diante de um choque externo e a consequente elevação do risco país, a política fiscal deveria ser instantaneamente ajustada de modo a promover um superavit primário suficiente para garantir a estabilidade da dívida pública como proporção do PIB, minimizando a necessidade de elevação dos juros. Caso contrário, a economia poderia convergir para um equilíbrio indesejável no qual a trajetória da dívida pública torna-se explosiva e o governo perderia o controle sobre a inflação. ${ }^{36}$

Essa análise possui três elementos centrais que merecem ser aqui destacados. Primeiramente, sob mobilidade de capitais, o câmbio flutuante não assegura por si só o sucesso da política monetária, que dependeria em última

(36) Esse processo é caracterizado como um caso clássico de transição de um regime de dominância monetária para um regime de dominância fiscal. Veja, por exemplo, Blanchard (2005). 
análise do ajuste fiscal. Os autores reconhecem que regimes comprometidos com metas de inflação, em economias emergentes abertas, possuem um importante componente cambial. No âmbito desse modelo, choques externos elevam o risco de default, promovendo uma redução dos influxos líquidos de capital externo (sudden stop). Sob câmbio flutuante, esse movimento se traduz numa desvalorização cambial, com impactos imediatos sobre a dívida pública denominada ou indexada ao dólar. Por outro lado, a variação cambial eleva imediatamente as expectativas de inflação doméstica. Sob um regime de metas, a autoridade monetária reage elevando a taxa real de juros. O resultado final, contudo, seria dependente do ajuste fiscal. Nenhuma alusão é feita à necessidade de isolar a economia doméstica de choques externos ou sobre o papel desestabilizador desempenhado pela mobilidade internacional de capitais nesse contexto. Ou seja, todo o peso do ajuste é deslocado para a elevação dos juros e sobretudo para a geração de expressivos superavits fiscais. Por fim, a análise supõe o produto real como dado. A hipótese subjacente, implicitamente reconhecida, é que políticas de contração da demanda agregada, monetárias ou fiscais, não têm efeito (direto) permanente sobre o produto e, portanto, sobre o crescimento da economia. Esse pressuposto exibe, assim, uma nítida sintonia com a concepção neoclássica de crescimento explicado pela oferta, conforme anteriormente explicitada.

Uma interpretação alternativa, em linhas pós-keynesianas, é oferecida por Oreiro et al. (2003). Essa visão reconhece que políticas monetárias e fiscais contracionistas têm um impacto negativo sobre o crescimento da economia, o qual, por sua vez, não pode ser razoavelmente ignorado numa análise realista sobre a dinâmica da dívida pública.

Utilizando esse arcabouço, sugerem uma estratégia para o crescimento econômico sustentado da economia, baseada em políticas macro menos restritivas que aquelas propostas pela abordagem convencional, câmbio administrado (crawling peg ativo) ${ }^{37}$ e controles sobre a entrada e a saída de capitais. O controle de capitais seria fundamental para isentar a política monetária doméstica da função de reduzir a pressão imposta pela alta volatilidade cambial, garantindo assim a autonomia das iniciativas domésticas de política econômica.

Nessa mesma linha teórica, Carvalho e Sicsú (2004) notam que supor regimes de câmbio flexível capazes de constituir alternativas factíveis ao controle de capitais, tanto no que se refere à garantia de políticas independentes quanto no que tange à absorção de choques externos, ignora pelo menos dois aspectos cruciais.

(37) A taxa de câmbio seria administrada de modo a manter a taxa real relativamente estável, evitando ao mesmo tempo uma sobrevalorização cambial e impactos indesejados sobre a taxa de inflação, por sua vez, administrada tendo em vista uma meta implícita definida pelo governo. 
Sérgio F. Meyrelles Filho / Frederico Gonzaga Jayme Jr./ Gilberto de Assis Libânio

Em primeiro lugar, a taxa de câmbio, notadamente em países emergentes, não é um preço comum, e sim um importante sinalizador das condições de operação da economia, para residentes e não residentes. Assim, variações cambiais (uma desvalorização cambial excessiva, por exemplo) podem servir para alimentar expectativas adversas e tornarem-se cumulativas em vez de autocorretivas (podendo resultar na formação de bolhas especulativas no mercado financeiro). Em segundo lugar, flutuações da taxa de câmbio podem gerar um efeito desorganizador sobre a economia de um país, tanto no que se refere a pressões inflacionárias quanto em relação ao nível de atividade. Os efeitos adversos poderiam advir em grande medida de uma volatilidade cambial excessiva, derivada do movimento instável dos fluxos internacionais de capital, capaz de acentuar a incerteza nos negócios, inibindo investimentos produtivos. Portanto, controles sobre os movimentos de capitais são advogados como uma possível forma de lidar com fluxos especulativos de capital e, portanto, de reduzir a volatilidade cambial sem sacrificar a autonomia da política monetária.

\section{Considerações finais}

O debate teórico aqui reportado deixa claro que os argumentos em prol da adoção de instrumentos de controle apontam para duas razões centrais como justificativas para restringir a livre mobilidade internacional dos fluxos de capital. A primeira delas é a redução da fragilidade externa das economias domésticas, ou seja, a redução de sua suscetibilidade a crises cambiais/financeiras diante de mudanças nas expectativas e humores dos investidores internacionais. A segunda relaciona-se à autonomia das políticas econômicas domésticas. Poderíamos também acrescentar uma terceira razão, relevante sob regimes de câmbio flexível, que é o controle da volatilidade cambial e de seus impactos desorganizadores sobre a economia. Considerados esses fatores, os críticos da liberalização financeira afirmam que, em algum grau, o controle sobre o movimento internacional de capitais é desejável no que se refere ao crescimento econômico de longo prazo, sobretudo no que diz respeito aos países em desenvolvimento.

Não obstante a plausibilidade teórica desses argumentos e o suporte conferido pela experiência mundial recente, marcada pela instabilidade financeira e reduzido crescimento econômico, concomitantemente ao intenso processo de liberalização deflagrado a partir da década de 1970, o fato é que, apesar de sua reconhecida importância, esse é, ainda, um tema relativamente pouco estudado fora das fronteiras do mainstream. Em particular, poucos esforços têm sido envidados para a construção de modelos formais, capazes de introduzir o controle de capitais como uma variável de escolha para a política econômica e de identificar canais de transmissão, mecanismos centrais, em sua relação com o processo de crescimento econômico de longo prazo. 
Julgamos que os princípios pós-keynesianos de crescimento liderado pela demanda e não neutralidade das políticas macro no longo prazo são componentes indispensáveis para um entendimento realista sobre a relação entre mobilidade de capitais e crescimento econômico. Entretanto, parcela expressiva dos modelos de crescimento liderado pela demanda, hoje existentes na literatura, tem como referência economias fechadas, ou simplesmente ignora as possíveis complicações introduzidas pelos fluxos internacionais de capital (e a possibilidade de controle sobre esses fluxos por decorrência). ${ }^{38}$ Os modelos kaldorianos de crescimento com restrição no balanço de pagamentos, a la McCombie e Thirlwall (1994; 1999), constituem em nosso entendimento um importante ponto de referência e uma via promissora para desenvolvimentos adicionais incorporando a possibilidade do controle de capitais. Esse é o sentido fundamental da contribuição aqui proposta e que é sugerido como tema de pesquisa. Um importante desafio consiste em identificar, dentro desse referencial analítico, uma rationale teórica para a existência de efeitos diferenciados da mobilidade de capitais nos países em desenvolvimento vis-à-vis as economias avançadas.

\section{Referências bibliográficas}

AIZENMAN, Joshua. Financial liberalization in Latin-America in the 1990s: a reassessment. Cambridge, Mass.: National Bureau of Economic Research, Feb. 2005. (NBER Working Paper Series, n. 11145).

ANDRADE, Joaquim Pinto de; SILVA, Maria Luiza Falcão. Divergências e convergências sobre as crises cambiais. In: LIMA, Gilberto Tadeu; SICSÚ, João; PAULA, Luiz Fernando de (Org.). Macroeconomia moderna: Keynes e a economia contemporânea. Rio de Janeiro: Campus, 1999. p. 306-327.

ARESTIS, Philip; GLICKMAN, Murray. Financial crisis in the Southeast Asia: dispelling illusion the Minskyan way. Cambridge Journal of Economics, v. 26, p. 237-260, 2002.

ATHANASOULIS, Stefano G.; WINCOOP, Eric van. Growth uncertainty and risksharing. Journal of Monetary Economics, v. 45, p. 477-505, 2000.

BARRO, Robert J. et al. Capital mobility in neoclassical models of growth. The American Economic Review, v. 85, n. 1, p. 103-115, Mar. 1995.

; SALA-I-MARTIN, Xavier. Economic growth. Cambridge: MIT Press, 2004.

(38) Um exemplo disso é fornecido por Lavoie (2004). O autor desenvolve um interessante modelo formal pós-keynesiano no qual o crescimento econômico é liderado pela demanda agregada. Seu argumento central é que políticas de juros altos, num regime de metas de inflação, exercem um efeito negativo sobre o crescimento da economia no longo prazo. Contudo, embora certamente relevante, o referido modelo não introduz as complicações relacionadas ao setor externo da economia. Da mesma forma, Dutt (1990) propõe um modelo de economia fechada sobre os efeitos reais de uma elevação da taxa de juros, considerando dois cenários possíveis, onde a economia opera, respectivamente, aquém ou no pleno emprego dos seus recursos de capital. O modelo mostra que num contexto onde existem recursos produtivos ociosos, um aumento dos juros eleva a inflação, piora a distribuição de renda e reduz o crescimento econômico de longo prazo. 
Sérgio F. Meyrelles Filho / Frederico Gonzaga Jayme Jr./ Gilberto de Assis Libânio

BARTOLINI, Leonardo; DRAZEN, Allan. Capital-account liberalization as a signal. The American Economic Review, v. 87, n. 1, p. 138-154, Mar. 1997.

BERNANKE, Ben S. Monetary policy in a world of mobile capital. Cato Journal, v. 25, n. 1, p. 1-12, 2005.

BORDO, Michael et al. Is the crisis problem growing more severe? Economic Policy, v. 16, n. 32, p. 53-82, Apr. 2001.

BLECKER, R. Taming global finance. Washington, DC, Economic Policy Institute, 1999.

CALVO, Guillermo; REINHART, Carmen. Fear of floating. Cambridge, Mass.: National Bureau of Economic Research, Nov. 2000. (NBER Working Paper Series, n. 7993).

; MENDOZA, Enrique. Rational contagion and the globalization of securities markets. In: CALVO, Guillermo (Ed.). Emerging capital markets in turmoil: bad luck or bad policy? Cambridge: MIT Press, 2005. p. 243-282.

CARVALHO, Fernando Cardim de. Políticas econômicas para economias monetárias. In: LIMA, Gilberto Tadeu; SICSÚ, João; Paula, Luiz Fernando de (Org.). Macroeconomia moderna: Keynes e a economia contemporânea. Rio de Janeiro: Campus, 1999. p. 258283.

; SICSÚ, João. Controvérsias recentes sobre controles de capitais. Revista de Economia Política, São Paulo, v. 24, n. 2, abr./jun. 2004.

COOPER, Richard N. Should capital-account convertibility be a world objective? Essays in International Finance, Princeton, n. 207, p. 11-19, 1998.

Should capital controls be banished? Brookings Papers on Economic Activity, Washington D. C., p. 89-125, 1999.

CURADO, Marcelo Luiz. Rigidez comercial, movimentos de capital e crise cambial. Tese (Doutorado)-Universidade Estadual de Campinas, Campinas, 2001.

DAVIDSON, Paul. Are grains of sand in the wheels of international finance sufficient to do the job when boulders are often required? The Economic Journal, n. 107, p. 671-686, May 1997.

. Volatile financial markets and the speculator. Economic Issues, v. 3, 1998.

Liquidity vs. efficiency in liberalized international financial markets: a warning to developing economies. Revista de Economia Política, São Paulo, v. 20, n. 3, p. 3-21, jul./set. 2000.

Resgatando a revolução keynesiana. In: LIMA, Gilberto Tadeu; SICSÚ, João. Macroeconomia do emprego e da renda: Keynes e o keynesianismo. Barueri: Manole, 2003, p. 3-28.

DOOLEY, Michael. Capital controls and emerging markets. International Journal of Finance and Economics, v. 1, p. 197-205, Jul. 1996.

DORNBUSCH, Rudiger. Capital controls: an idea whose time is past. Essays in International Finance, Princeton, n. 207, p. 20-27, 1998.

DUTT, A. Interest rate policy in LDCs: a post Keynesian view. Journal of Post Keynesian Economics, v. 13, n. 2, p. 210-232, 1990. 
DUTT, A. Equilibrium, path dependence and hysteresis in post keynesian models. In: ARESTIS, Philip et al. Markets, unemployment and economic policy - essays in honor of Geoff Harcourt. New York: Routledge, 1997, p. 238-253.

EATWELL, John. International financial liberalization: the impact on world development. New York, USA, 1996. (CEPA Working Paper, n. 1).

EDWARDS, Sebastian. How effective are capital controls? Cambridge, Mass.: National Bureau of Economic Research, Nov. 1999. (NBER Working Paper Series, n. 7413).

; KHAN, Mohsin S. Interest rate determination in developing countries: a conceptual framework. Cambridge, Mass.: National Bureau of Economic Research, Jan. 1985. (NBER Working Paper Series, n. 1531).

EICHENGREEN, Barry. Capital account liberalization: what do cross-country studies tell us? The World Bank Economic Review, v. 15, n. 3, p. 341-365, 2001.

et al. Capital account liberalization: theoretical and practical aspects. Occasional Paper, Washington D. C., IMF, n. 172, 1998.

FAVERO, Carlos A.; GIAVAZZI, Francesco. Inflation targeting and debt: lessons from Brazil. In: GIAVAZZI, Francesco et al. (Ed.). Inflation targeting, debt, and the Brazilian experience, 1999 to 2003. Cambridge: MIT Press, 2005. p. 85-108.

FISCHER, Stanley. Capital-account liberalization and the role of the IMF. Essays in International Finance, Princeton, n. 207, p. 1-10, 1998.

FLOOD, Robert; MARION, Nancy. Perspectives on the recent currency crisis literature. In: CALVO, Guilhermo et al. (Ed.). Money, capital mobility, and trade: Essays in honor of Robert Mundell. Cambridge: MIT Press, 2001.

FOLEY, Duncan K. Financial fragility in developing economies. In: DUTT, Amitava K.; ROSS, Jaime. Development economics and structuralist macroeconomics. Cheltenham: Edward Elgar, 2003, p. 157-168.

FRY, Maxwell J. Money, interest and banking in economic development. Baltimore: John Hopkins University. 1995.

GOURINCHAS, Pierre-Olivier; JEANNE, Olivier. On the benefits of capital account liberalization for emerging economies. CEPR, Jun. 2002.

. The elusive gains from international financial integration. Cambridge, Mass.: National Bureau of Economic Research, May 2003. (NBER Working Paper Series, n. 9684).

GRABEL, Ilene. Averting crisis? Assessing measures to manage financial integration in emerging economies. Cambridge Journal of Economics, v. 27, p. 317-336, 2003.

GREENWALD, Bruce C.; STIGLITZ, Joseph E. Externalities in economies with imperfect information and incomplete markets. The Quarterly Journal of Economics, p. 229-264, May 1986.

GROSSMAN, Sanford J.; STIGLITZ, Joseph E. Information and competitive price systems. American Economic Review, v. 66, p. 246-253, May 1976. 
Sérgio F. Meyrelles Filho / Frederico Gonzaga Jayme Jr./ Gilberto de Assis Libânio

KEYNES, John Maynard. A teoria geral do emprego, do juro e da moeda. São Paulo: Nova Cultural, 1996.

KREGEL, Jan A. Economic methodology in the face of uncertainty: the modelling methods of Keynes and the post-keynesians. The Economic Journal, n. 86, p. 209-225, Jun. 1976.

Yes, 'It' did happened again: a Minsky crisis happened in Asia. New York: The Jerome Levy Economics Institute, Apr. 1998. (Working Paper, n. 234).

KREGEL, Jan A. Havia alternativa à crise brasileira? In: VELLOSO, João Paulo dos Reis (Coord.). A crise mundial e a nova agenda de crescimento. Rio de Janeiro: José Olympio, 1999. p. 137-157.

KRUGMAN, Paul. What happened to Asia?. Cambridge, Jan. 1998. Disponível em: http://web.mit.edu/krugman/www/DISINTER.html. Acesso em: 10 set. 2003.

LEVINE, Ross. Financial development and economic growth: Views and agenda. Journal of Economic Literature, v. 35, p. 688-726, Jun. 1997.

LIBÂNIO, Gilberto A. "Good governance" in monetary policy and the negative real effects of inflation targeting in developing economies. Belo Horizonte: CEDEPLARUFMG, dez. 2005. (Texto para Discussão, n. 277).

McCOMBIE, J. S. L.; THIRLWALL, A. P. Economic growth and the balance-ofpayments constraint. New York: St. Martins Press, 1994.

Growth in an international context: a post-keynesian view. In: DEPREZ, J.; HARVEY, J. T. (Ed.). Foundations of international economics: post keynesian perspectives. London: Routledge, 1999.

MINSKY, Hyman. Money, financial markets, and the coherence of market economy. Journal of Post Keynesian Economics, v. 3, n. 1, 1980.

. The financial instability hypothesis. New York: The Jerome Levy Economics Institute, May 1992. (Working Paper, n. 74).

MISHKIN, Frederic S. Lessons from the Asian crisis. Cambridge, Mass.: National Bureau of Economic Research, Apr. 1999. (NBER Working Paper Series, n. 7102).

OBSTFELD, Maurice. Risk-taking, global diversification, and growth. The American Economic Review, v. 84, n. 5, Dec. 1994.

The global capital market: Benefactor or menace? Journal of Economic Perspectives, v. 14, p. 9-30, 1998.

; ROGOFF, Kenneth. Foundations of international macroeconomics. Cambridge: MIT Press, 1996.

OREIRO, José Luís et al. Controle da dívida pública e política fiscal: uma alternativa para um crescimento auto-sustentado da economia brasileira. In: SICSÚ, João et al. Agenda Brasil: políticas econômicas para o crescimento com estabilidade de preços. Barueri: Manole, 2003. p. 117-152. 
OREIRO, José Luís. Autonomia de política econômica, fragilidade externa e equilíbrio do balanço de pagamentos: a teoria econômica dos controles de capitais. Economia $e$ Sociedade, Campinas, v. 13, n. 2 (23), p. 1-22, jul./dez. 2004.

PRASAD, Eswar et al. Financial globalization, growth and volatility in developing countries. Cambridge, Mass.: National Bureau of Economic Research, Dec. 2004. (NBER Working Paper Series, n. 10942).

RODRIK, Dani. Who needs capital-account convertibility? Essays in International Finance, Princeton, n. 207, p. 55-65, 1998.

; VELASCO, Andres. Short term capital flows. Cambridge, Mass.: National Bureau of Economic Research, Sept. 1999. (NBER Working Paper Series, n. 7364).

ROGOFF, Kenneth. Rethinking capital controls: When should we keep an open mind? Finance \& Development: A quarterly magazine of the IMF, Washington, D.C., v. 39, n. 4, p. 1-5, Dec. 2002.

ROMER, David. Advanced macroeconomics. New York: McGraw-Hill, 2005.

SICSÚ, J.; FERRARI FILHO, F. Câmbio e controles de capitais. Rio de Janeiro: Elsevier, 2006.

SETTERFIELD, Mark. (Org.). The economics of demand-led growth. Cheltentam: Edward Elgar, 2002.

STIGLITZ, Joseph E. Endogenous growth and cycles. Cambridge, Mass.: National Bureau of Economic Research, Mar. 1993. (NBER Working Paper Series, n. 4286).

Capital market liberalization, economic growth, and instability. World Development, v. 28, n. 6, p. 1075-1086, 2000.

. Globalization and growth in emerging markets and the new economy. Journal of Policy Modeling, v. 25, p. 505-524, 2003.

; WEISS, Andrew. Credit rationing in markets with imperfect information. American Economic Review, v. 71, n. 3, p. 393-410, Jun. 1981.

TAYLOR, Lance. Capital market crises: Liberalization, fixed exchange rates and marketdriven destabilisation. Cambridge Journal of Economics, v. 22, p. 663-676, 1998.

TOBIN, James. A proposal for international monetary reform. Eastern Economic Journal, v. 4, n. 3-4, p. 153-159, Jul./Oct. 1978.

WILLIAMSON, John; MAHAR, Molly. A survey of financial liberalization. Essays in International Finance, Princeton, n. 211, p. 1-70, 1998. 